\title{
Patterns of Gustatory Recovery in Patients Affected by the COVID-19 Outbreak
}

\author{
Carlos M. Chiesa-Estomba ${ }^{1,2,3}$ (1) Jerome R. Lechien ${ }^{1,4,5,6} \cdot$ Maria R. Barillari $^{1,7} \cdot$ Sven Saussez $^{8}$
}

Received: 28 June 2020 / Accepted: 15 July 2020 / Published online: 3 August 2020

(c) Wuhan Institute of Virology, CAS 2020

\section{Dear Editor,}

Coronavirus disease 2019 (COVID-19) is a viral infection caused by severe acute respiratory syndrome coronavirus 2 (SARS-CoV-2). From March 2020, several studies indicate that many subjects affected by mild-to-moderate COVID-19 presented olfactory/gustatory dysfunction (OD/GD) that appeared strongly correlated between them but not with the other symptoms suggestive of upper airway infection (Lechien et al. 2020a, b; Hopkins et al. 2020; Paderno et al. 2020).

Isolated OD and GD, without any other general or otolaryngologycal complaints like rhinorrhea or nasal obstruction, were also described as the main or unique

Carlos M. Chiesa-Estomba

chiesaestomba86@gmail.com

1 COVID-19 Task Force of the Young-Otolaryngologists of the International Federations of Oto-rhino-laryngological Societies (YO-IFOS), Paris, France

2 Department of Otorhinolaryngology-Head and Neck Surgery, Osakidetza, Hospital Universitario Donostia, San Sebastian 20014, Spain

3 Biodonostia Health Research Institute, San Sebastian 20014, Spain

4 Department of Human Anatomy and Experimental Oncology, Faculty of Medicine, UMONS Research Institute for Health Sciences and Technology, University of Mons (UMons), 7000 Mons, Belgium

5 Department of Otolaryngology-Head and Neck Surgery, Foch Hospital, School of Medicine, UFR Simone Veil, Université Versailles Saint-Quentin-en-Yvelines (Paris Saclay University), Paris 92150, France

6 Department of Otorhinolaryngology and Head and Neck Surgery, CHU de Bruxelles, CHU Saint-Pierre, School of Medicine, Université Libre de Bruxelles, Brussels 1000, Belgium

7 Department of Mental and Physical Health and Preventive Medicine, "L. Vanvitelli" University, 80138 Naples, Italy

8 Department of Head and Neck Surgery, EpiCURA Hospital, Hornu 7331, Belgium symptoms of the infection in a variable percentage of cases; these patients, not initially identified as infected, could have represented a potential way to rapidly spread the infection among the population (Lechien et al. 2020b; Vaira et al. 2020).

Post-viral gustatory dysfunction is well established, has been shown to be a key symptom of the coronavirus diseases 2019 (COVID-19), with more than 50\% European and U.S mild to moderate patients reporting some degree of loss of taste (Hopkins et al. 2020; Lechien et al. 2020b; Yan et al. 2020). We have apparently overcome the worst part of the initial outbreak. However, persistent GD appears to be commonplace and will drive the demand for general practitioner, otolaryngology or neurology consultation in the next months-evidence regarding recovery will be essential in counselling our patients.

In order to evaluate patterns of gustatory recovery, data from patients with confirmed mild COVID-19 were collected prospectively from four university hospitals. Inclusion and exclusion criteria were described in Fig. 1. All patients had at least 30-days of follow-up after their last negative subsequent COVID-19 test. Information was collected using an online questionnaire created with Professional Survey Monkey (San Mateo, California, USA). Informed consent was obtained. Data may be available upon a reasonable request and an approval from the originating university hospitals.

Relevant epidemiological and clinical features contained within the questionnaire were collected by the COVID-19 Study Group of Young Otolaryngologists of the International Federation of Oto-rhino-laryngological Societies (YO-IFOS), and consisted of four subsets (demographic data, medical background, ENT symptoms and olfactory and gustatory dysfunction). All patients completed the Short version of Questionnaire of Olfactory DisordersNegative Statements (sQOD-NS) (Mattos et al. 2019). The remaining olfactory and taste questions were based on the smell and taste component of the National Health and Nutrition Examination Survey (Bhattacharyya and Kepnes 


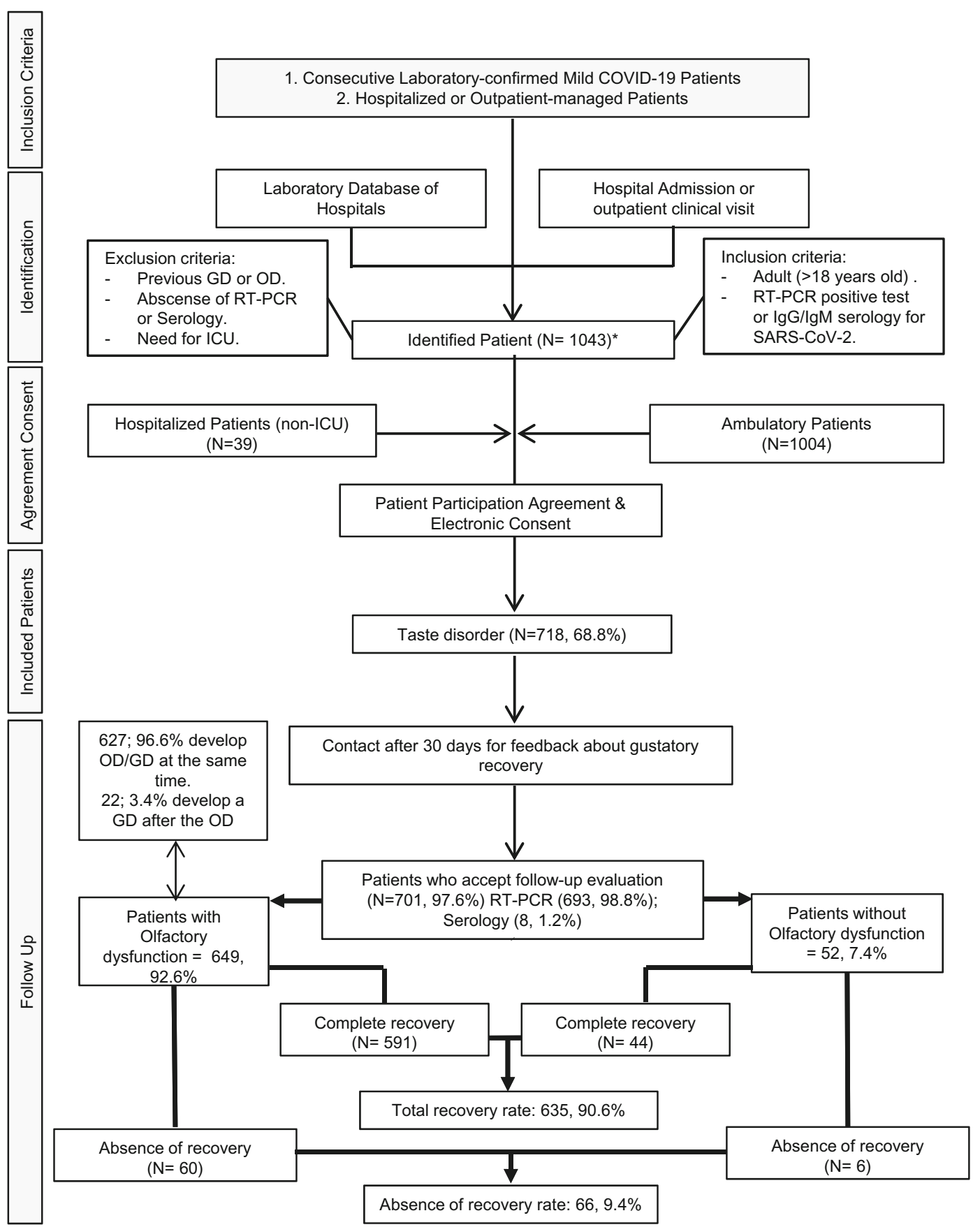

Fig. 1 Gustatory dysfunction flowchart. * Those patients with symptom duration $<14$ days were tested with a nasopharyngeal swab; in the case of three negative RT-PCR or patients with symptoms for $\geq 14$ days, serology testing was performed.

2015). Physical examination (rhinoscopy, nasal endoscopy or objective olfactory or gustatory testing) was not performed in this study due to the risk of nosocomial infection.

Statistical Package for the Social Sciences for Windows (SPSS version 21,0; IBM Corp, Armonk, NY, USA) was used to perform the statistical analyses. The potential associations between epidemiological, clinical and gustatory outcomes have been assessed through cross-tab generation between two variables (binary or categorical variables) and Chi square test. Incomplete responses were excluded from analysis. A level of $P<0.05$ was used to determine statistical significance. A multivariate analysis (MA) was performed to address possible confounders. Part of this data was previously published in other papers (Lechien et al. 2020a, b, c; Chiesa-Estomba et al. 2020).

All told, 1043 patients identified in the emergency room or primary care consultation were invited and agreed to 
Table 1 Demographic and clinical data.

\begin{tabular}{|c|c|c|c|c|}
\hline Characteristics & All patients $=701$ & $\%$ & $P$ & M.A. \\
\hline Median age (Years) & $40 \pm 13$ (range: $18-78$ ) & & & \\
\hline Sex & & & 0.001 & 0.003 \\
\hline Male & 230 & 32.8 & & \\
\hline Female & 471 & 67.2 & & \\
\hline Ethnicity & & & 0.791 & 0.346 \\
\hline European & 558 & 79.6 & & \\
\hline Latin-American & 136 & 19.4 & & \\
\hline North American & 2 & 0.3 & & \\
\hline North-African & 2 & 0.3 & & \\
\hline Sub-Saharan African & 2 & 0.3 & & \\
\hline Current Smoker & 83 & 11.8 & 0.334 & 0.291 \\
\hline History of seasonal allergy & 121 & 17.2 & 0.276 & 0.301 \\
\hline \multicolumn{5}{|l|}{ Comorbidities } \\
\hline Diabetes & 18 & 2.6 & 0.271 & 0.683 \\
\hline Heart problems & 15 & 2.1 & 0.555 & 0.511 \\
\hline COPD & 6 & 0.9 & 0.767 & 0.871 \\
\hline Hypertension & 47 & 6.7 & 0.654 & 0.391 \\
\hline Asthma & 41 & 5.8 & 0.433 & 0.213 \\
\hline Hypothyroidism & 44 & 6.3 & 0.267 & 0.379 \\
\hline Autoimmune disease (LES, RA) & 27 & 3.9 & 0.301 & 0.411 \\
\hline \multicolumn{5}{|l|}{ General symptoms } \\
\hline Headache & 539 & 72.6 & 0.001 & 0.009 \\
\hline Myalgia & 494 & 66.6 & 0.411 & 0.395 \\
\hline Cough & 373 & 51 & 0.062 & 0.008 \\
\hline Loss of appetite & 418 & 56.6 & 0.598 & 0.541 \\
\hline Dyspnea & 39 & 5.8 & 0.911 & 0.934 \\
\hline Diarrhea, Abdominal pain & 281 & 39.3 & 0.466 & 0.093 \\
\hline Fever $(>38 \mathrm{C})$ & 261 & 36.2 & 0.051 & 0.035 \\
\hline Arthralgia & 359 & 49.5 & 0.467 & 0.402 \\
\hline Nausea, vomiting & 140 & 19.7 & 0.541 & 0.387 \\
\hline Sticky mucus/phlegm & 121 & 17.3 & 0.219 & 0.314 \\
\hline \multicolumn{5}{|l|}{ Ear, nose and throat Symptoms } \\
\hline Nasal obstruction & 108 & 15.4 & 0.413 & 0.367 \\
\hline Olfactory dysfunction & 649 & 92.6 & 0.001 & 0.001 \\
\hline Sore throat & 189 & 26.2 & 0.404 & 0.635 \\
\hline Rhinorrhea & 79 & 12.5 & 0.433 & 0.391 \\
\hline Postnasal drip & 90 & 13.4 & 0.212 & 0.566 \\
\hline Face pain/heaviness & 103 & 16.6 & 0.133 & 0.418 \\
\hline Ear pain & 30 & 4.1 & 0.871 & 0.793 \\
\hline Dysphagia & 64 & 9.2 & 0.398 & 0.501 \\
\hline
\end{tabular}

Abbreviations: MA: multivariate analysis; SEL: systemic lupus; RA: Rheumatoid arthritis. participate in the study. Among them 718 (68.8\%) described a GD. 701 patients completed the study (Fig. 1). The mean age of patients was $40 \pm 13$ (range: 18-78). There were 471 females and 230 males. Patients were grouped according the presence or absence of olfactory dysfunction. Both groups were comparable according to age, sex ratio, comorbidities and addiction $(P=0.273$, Wilcoxon). Of those patients who reported GD, there were 649 patients (92.6\%) who subjectively report a partial or total loss of smell. By contrast, 52 (7.4\%) did not report OD. About general symptoms, headache, cough and fever were the most common in those patients who develop a GD. After a mean follow-up of $63 \pm 9$ days (range: 60-76) from the first consultation, $66(9.4 \%)$ of patients still reported a 
persistent subjective GD and 635 (90.6\%) reported complete recovery. There was a statistical correlation between GD and OD $(P=0.001)$. However, no difference in the rate of gustatory recovery according to the presence or absence of olfactory dysfunction was encountered $(P=0.952)$. The mean duration of the GD was $11 \pm 5$ days (range: $3-36$ ) in those patients who recovered (Fig. 1). There was no significant association between comorbidities and the development or persistence of GD. Other possible confounders rather than OD were identified according to our MA (Table 1).

Taste sense correspond to an integrative experience that involves the correlation of information from oral cavity mucosal surfaces through numerous peripheral cranial nerves and other sensory modalities, such as olfaction and somatosensation (Daly et al. 2012). The prevalence of selfreported gustatory dysfunction in our study was similar to those previously reported in COVID-19 patients (Lechien et al. 2020a, b; Hopkins et al. 2020; Paderno et al. 2020; Vaira et al. 2020). However, the frequency of residual GD after 60 days of follow-up was significantly low. According to our results and similarly to previous report, GD is related to OD. Despite the rate of recovery was higher in those patients without OD, we were not able to find statistical differences among groups. According to our findings, we consider highlighting the presence of isolated GD in at least $7 \%$ of our patients.

At this moment, the molecular mechanisms of GD in COVID-19 patients remain still unclear. Regarding taste, it depends on the activity of specialized epithelial cells and taste cells, which are located mainly in the tongue mucosa. Shigemura et al. recently found that renin-angiotensin system (RAS) components as well as angiotensin-converting enzyme- 2 (ACE-2) are expressed in mouse taste organs and are present in the taste buds of fungiform and circumvallate papillae with $\mathrm{ENaC}$ (epithelial sodium channel -subunit, a salt taste receptor) or T1R3 (taste receptor type 1 member 3 , a sweet taste receptor component). These preliminary results indicate the existence of a local RAS in the taste organ and suggest that taste function may be regulated by both locally-produced and circulating angiotensin II (Shigemura et al. 2019).

It is well known that SARS-CoV-2 binds directly to the ACE2 cell receptors to infect humans and it has been reported that ACE2 is the main host cell receptor of SARS$\mathrm{CoV}-2$, playing a crucial role in the entry of virus inside the cell to cause the final infection (Hoffmann et al. 2020). ACE2 receptors were also identified in brain and have been detected over glial cells and neurons (Netland et al. 2008). However, more evidence is necessary to elucidate the real mechanism for the GD.

Limitations of this study are the exclusion of patients with severe disease, the small proportion of older patients, the higher proportion of female respondents, loss to followup and recruitment from ENT-Clinics, potentially introducing a selection bias. Lack of objective testing to confirm GD is also a limitation. Also, the fact that retro-olfaction is essential for taste. However, at this relatively early point in the pandemic, subjective patterns of recovery of GD in COVID-19 patients are valuable for our patients, hypothesis generation and treatment development.

\section{Compliance with Ethical Standards}

Conflict of interest The authors declare that they have no conflict of interest.

Animal and Human Rights Statement Four ethics committees approved the current study protocol (HAP2020-011; CHUSP20032020; EpiCURA-2020-2303; CHUCharleroi:B32522020).

\section{References}

Bhattacharyya N, Kepnes LJ (2015) Contemporary assessment of the prevalence of smell and taste problems in adults. Laryngoscope 125:1102-1106

Chiesa-Estomba CM, Lechien JR, Portillo-Mazal P, Martínez F, Cuauro-Sanchez J, Calvo-Henriquez C, Saussez S (2020) Olfactory and gustatory dysfunctions in COVID-19 First reports of Latin-American ethnic patients. Am J Otolaryngol 41:102605

Daly BP, Daly MP, Minniti N, Daly JM (2012) Sense of taste (Effect on Behavior), encyclopedia of human behavior, 2nd edn. Academic Press, Cambridge, pp 373-378

Hoffmann M, Kleine-Weber H, Schroeder S, Krüger N, Herrler T, Erichsen S, Schiergens TS, Herrler G, Wu NH, Nitsche A, Müller MA, Drosten C, Pöhlmann S (2020) SARS-CoV-2 cell entry depends on ACE2 and TMPRSS2 and is blocked by a clinically proven protease inhibitor. Cell 181:271-280

Hopkins C, Surda P, Kumar N (2020) Presentation of new onset anosmia during the COVID-19 pandemic. Rhinology 58:295-298

Lechien JR, Chiesa-Estomba CM, Place S, Van Laethem Y, Cabaraux P, Mat Q, Huet K, Plzak J, Horoi M, Hans S, Rosaria Barillari M, Cammaroto G, Fakhry N, Martiny D, Ayad T, Jouffe L, Hopkins C, Saussez S, COVID-19 Task Force of YO-IFOS (2020a) Clinical and epidemiological characteristics of 1420 European patients with mild-to-moderate coronavirus disease 2019. J Intern Med. https://doi.org/10.1111/joim.13089

Lechien JR, Chiesa-Estomba CM, De Siati DR, Horoi M, Le Bon SD, Rodriguez A, Dequanter D, Blecic S, El Afia F, Distinguin L, Chekkoury-Idrissi Y, Hans S, Delgado IL, Calvo-Henriquez C, Lavigne P, Falanga C, Barillari MR, Cammaroto G, Khalife M, Leich P, Souchay C, Rossi C, Journe F, Hsieh J, Edjlali M, Carlier R, Ris L, Lovato A, De Filippis C, Coppee F, Fakhry N, Ayad T, Saussez S (2020b) Olfactory and gustatory dysfunctions as a clinical presentation of mild-to-moderate forms of the coronavirus disease (COVID-19): a multicenter European study. Eur Arch Otorhinolaryngol. https://doi.org/10.1007/s00405-02005965-1

Lechien JR, Chiesa-Estomba CM, Hans S, Barillari MR, Jouffe L, Saussez S (2020c) Loss of smell and taste in 2013 European 
patients with mild to moderate COVID-19. Ann Int Med. https:// doi.org/10.7326/M20-2428

Mattos JL, Edwards C, Schlosser RJ, Hyer M, Mace JC, Smith TL, Soler ZM (2019) A brief version of the questionnaire of olfactory disorders in patients with chronic rhinosinusitis. Int Forum Allergy Rhinol 9:1144-1150

Netland J, Meyerholz DK, Moore S, Cassell M, Perlman S (2008) Severe acute respiratory syndrome coronavirus infection causes neuronal death in the absence of encephalitis in mice transgenic for human ACE2. J Virol 82:7264-7275

Paderno A, Schreiber A, Grammatica A, Raffetti E, Tomasoni M, Gualtieri T, Taboni S, Zorzi S, Lombardi D, Deganello A, Redaelli De Zinis LO, Maroldi R, Mattavelli D (2020) Smell and taste alterations in COVID-19: a cross-sectional analysis of different cohorts. Int Forum Allergy Rhinol. https://doi.org/10. 1002/alr.22610
Shigemura N, Takai S, Hirose F, Yoshida R, Sanematsu K, Ninomiya $\mathrm{Y}$ (2019) Expression of renin-angiotensin system components in the taste organ of mice. Nutrients 11:2251

Vaira LA, Hopkins C, Salzano G, Petrocelli M, Melis A, Cucurullo M, Ferrari M, Gagliardini L, Pipolo C, Deiana G, Fiore V, De Vito A, Turra N, Canu S, Maglio A, Serra A, Bussu F, Madeddu G, Babudieri S, Giuseppe Fois A, Pirina P, Salzano FA, De Riu P, Biglioli F, De Riu G (2020) Olfactory and gustatory function impairment in COVID-19 patients: Italian objective multicenterstudy. Head Neck 42:1560-1569

Yan CH, Faraji F, Prajapati DP, Ostrander BT, DeConde AS (2020) Self-reported olfactory loss associates with outpatient clinical course in Covid-19. Int Forum Allergy Rhinol 10:821-831 